\title{
Thermal Stability of Hf-based High- $\kappa$ Dielectric Films on Si(100)
}

\author{
M.J. Kim, ${ }^{*}$ J. Huang, ${ }^{*}$ D.K. Cha, ${ }^{*}$ M.A. Quevedo-Lopez, ${ }^{* *}$ R.M. Wallace, ${ }^{*}$ and B.E. Gnade* \\ *Department of Materials Science and Engineering, University of North Texas, Denton, TX 76203 \\ **Silicon Technology Development, Texas Instruments, Inc., Dallas, Texas 75265
}

As the scaling of silicon integrated circuits continues, the problem of direct tunneling leakage current due to the reduced thickness of current gate dielectric films such as $\mathrm{SiO}_{2}$ and $\mathrm{SiO}_{\mathrm{x}} \mathrm{N}_{\mathrm{y}}$ should be resolved [1]. For this, high- $\kappa$ gate dielectrics become one of the solutions in providing increased capacitance without remarkable increase in gate leakage current. This poses a very important technological problem whose solution depends on the structure, chemistry, and properties of new alternate gate dielectrics exhibiting higher $\kappa$. Some important requirements include thermal stability, smooth interfaces, dopant diffusion resistance, etc. For this study, we present results on the thermal stability of Hf-based films that have been proposed as suitable candidates for advanced gate dielectric applications [2].

Current gate dielectric $\mathrm{SiO}_{2}$ thin films are thermally stable as shown in Figure 1. The as-deposited gate oxide is amorphous and is about $1.5 \mathrm{~nm}$ thick. Its structure is unchanged after rapid thermal annealing at $1050^{\circ} \mathrm{C}$ for $60 \mathrm{sec}$, as expected. A thicker $\mathrm{SiO}_{2}$ gate oxide is also thermally stable at this temperature. Hf-silicate $\left(\mathrm{HfSi}_{\mathrm{x}} \mathrm{O}_{\mathrm{y}}\right)$ films deposited by chemical vapor deposition methods on $\mathrm{Si}(100)$ are shown in Figure 2. The as-deposited film is amorphous and contains a thin $\mathrm{SiO}_{\mathrm{x}}$ interfacial layer. No crystallization was observed in Hf-silicate films after RTA annealing up to 60 sec below $950^{\circ} \mathrm{C}$. However, early stage of crystallization is observed after RTA anneal at $950^{\circ} \mathrm{C}$ for $60 \mathrm{sec}$. Crystallization becomes more evident upon further annealing at $1050^{\circ} \mathrm{C}$, as shown in Figure 2b. The observed nano-crystals appear to be $\mathrm{HfO}_{2}$, not Hf-silicate, which is consistent with the fact that the crystallization temperature of $\mathrm{HfO}_{2}$ is lower than the one of $\mathrm{HfSi}_{\mathrm{x}} \mathrm{O}_{\mathrm{y}}$. Our earlier results showed an enhanced B diffusivity in these annealed films [3], suggesting enhanced diffusion along newly formed grain boundaries of $\mathrm{HfO}_{2}$ nanocrystals.

The incorporation of $\mathrm{N}$ is known to be useful in improving thermal stability as well as minimizing dopant diffusion [4]. Figure 3 illustrates the effects of $\mathrm{N}$ incorporation into $\mathrm{HfSi}_{\mathrm{x}} \mathrm{O}_{\mathrm{y}}$ where no crystallization is observed after the annealing at $1050^{\circ} \mathrm{C}$ for $60 \mathrm{sec}$. $\mathrm{HfSi}_{\mathrm{x}} \mathrm{O}_{\mathrm{y}} \mathrm{N}_{\mathrm{z}}$ films were deposited by reactive sputtering methods, with $\mathrm{Hf}$ content of $\sim 5-6$ at.\% and $\sim 18$ at.\% N. Suppression of crystallization observed in $\mathrm{HfSi}_{\mathrm{x}} \mathrm{O}_{\mathrm{y}} \mathrm{N}_{\mathrm{z}}$ films can be attributed to the incorporation of $\mathrm{N}$ and low $\mathrm{Hf}$ content in the films. $\mathrm{HfSi}_{\mathrm{x}} \mathrm{O}_{\mathrm{y}} \mathrm{N}_{\mathrm{z}}$ films with higher $\mathrm{Hf}$ content were also thermally stable after a "spike" anneal at $1050^{\circ} \mathrm{C}$ for $1 \mathrm{sec}$, but crystallization was observed after $60 \mathrm{sec}$ (see Figure 4) [5].

\section{References}

[1] International Roadmap for Semiconductors (http//public.itrs.net), Semiconductor Industry Association, San Jose, CA, 2001.

[2] G.D. Wilk, R.M. Wallace, and J.M. Anthony, J. Appl. Phys. 89 (2001) 5243.

[3] M.A. Quevedo-Lopez et al., Appl. Phys. Lett. 81 (2002) 1074.

[4] T. Hori, Gate Dielectrics and MOS ULSI's, Springer, New York, 1997.

[5] This research was supported by the SRC and the Texas Advanced Technology Program. The authors thank Drs. M. Visokay, L. Colombo and J.J. Chambers (TI) for the samples. 

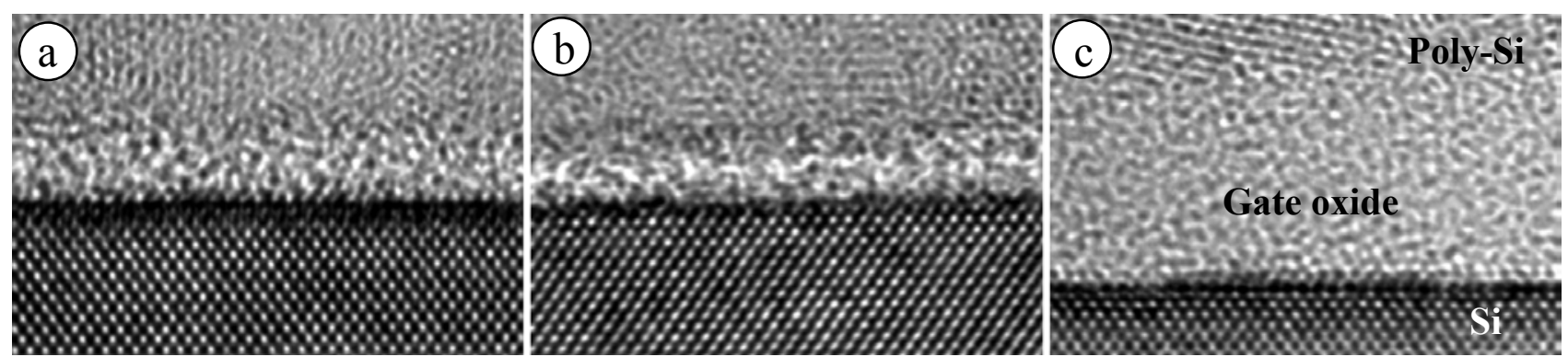

FIG. 1. Cross-sectional HREM images of poly-Si/SiO $2 / \mathrm{Si}$ interfaces: (a) as-deposited and (b) after rapid thermal annealing (RTA) at $1050^{\circ} \mathrm{C}$ for $60 \mathrm{sec}$. (c) Thick gate oxide after RTA at $1050^{\circ} \mathrm{C}$ for $60 \mathrm{sec}$. The observed amorphous $\mathrm{SiO}_{2}$ gate oxides are thermally stable, as expected at this temperature $\left(1050^{\circ} \mathrm{C}\right)$. Z.A. $=\mathrm{Si}[110]$.
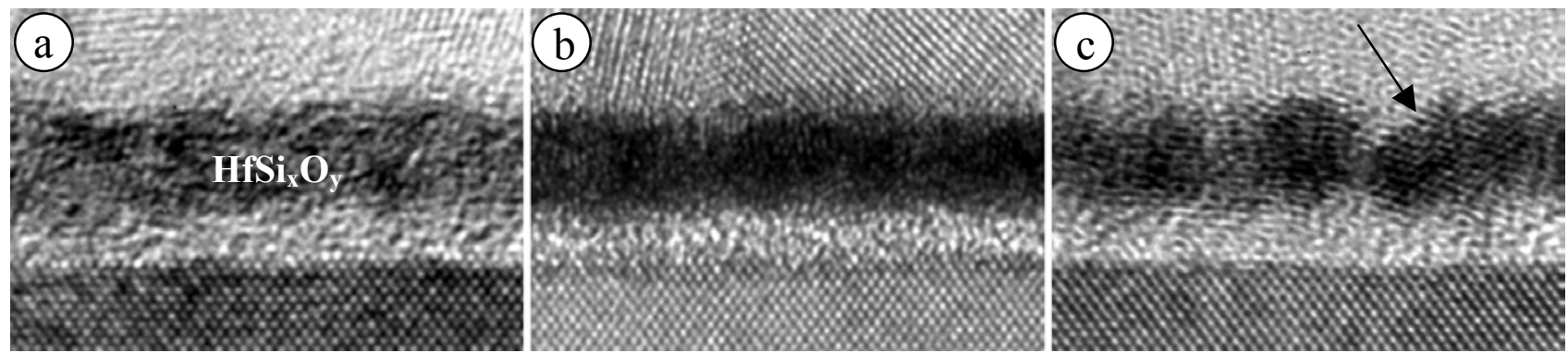

FIG. 2. HREM images of the poly-Si capped Hf-silicate thin films on $\mathrm{Si}(100)$ : (a) as-deposited, and $60 \mathrm{sec}$ RTA at (b) $950^{\circ} \mathrm{C}$ and (c) $1050^{\circ} \mathrm{C}$. The as-deposited Hf-silicate film is amorphous. $\mathrm{SiO}_{\mathrm{x}}$ interfacial layer is observed. Note nano-crystalline nature of the Hf-silicate film annealed at $1050^{\circ} \mathrm{C}$. The observed nanocrystals appear to be $\mathrm{HfO}_{2}$, not Hf-silicate. Z.A. $=\mathrm{Si}[110]$.

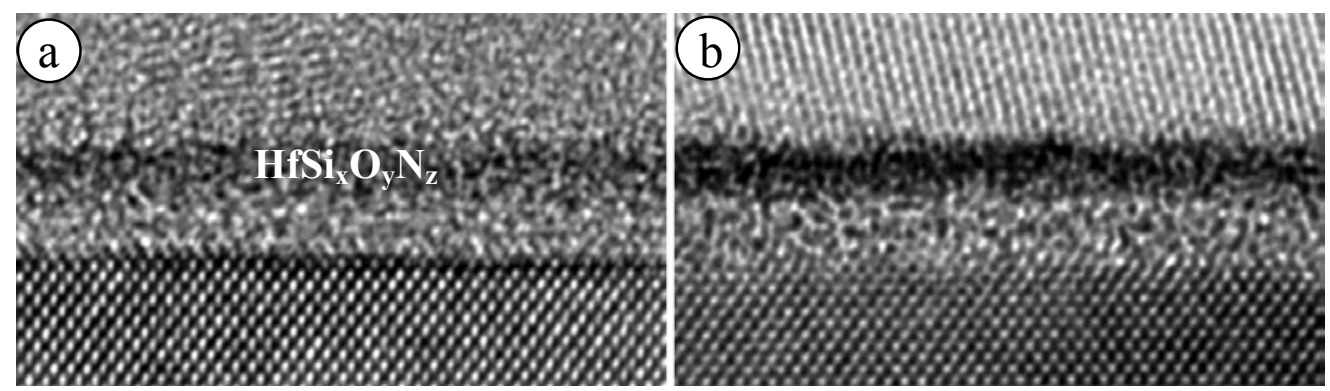

FIG. 3. Cross-sectional HREM images of the poly-Si capped $\mathrm{HfSi}_{\mathrm{x}} \mathrm{O}_{\mathrm{y}} \mathrm{N}_{\mathrm{z}}$ thin films on $\mathrm{Si}(100)$ : (a) asdeposited and (b) $60 \mathrm{sec}$ RTA at $1050^{\circ} \mathrm{C}$. No crystallization is observed in $\operatorname{HfSi}_{\mathrm{x}} \mathrm{O}_{\mathrm{y}} \mathrm{N}_{\mathrm{z}}$ films. Z.A. $=\mathrm{Si}[110]$.
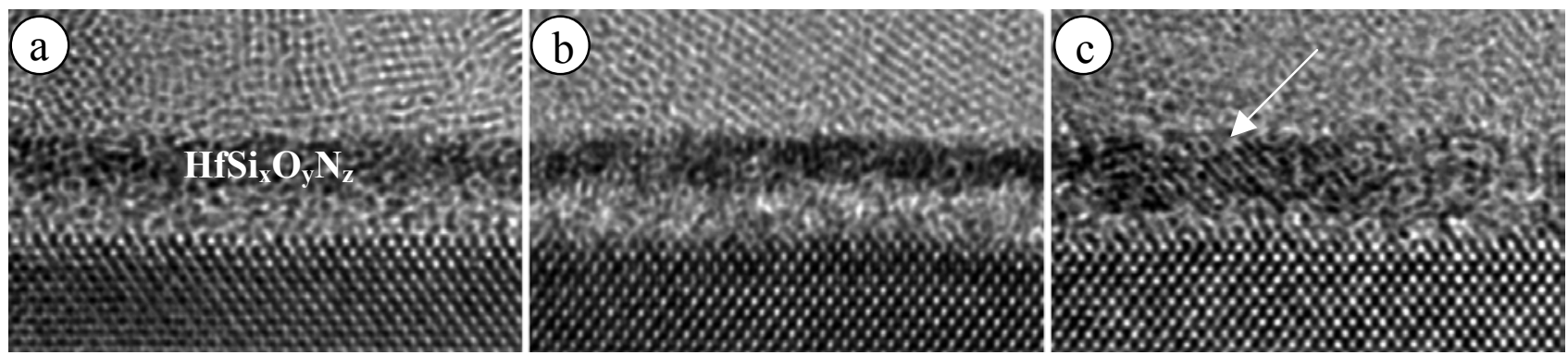

FIG. 4. Cross-sectional HREM images of the poly-Si capped $\mathrm{HfSi}_{\mathrm{x}} \mathrm{O}_{\mathrm{y}} \mathrm{N}_{\mathrm{z}}$ thin films with higher Hf content, compared with Fig. 3, on $\mathrm{Si}(100)$ : (a) as-deposited, (b) $1 \mathrm{sec}$, and (c) $60 \mathrm{sec}$ RTA at $1050^{\circ} \mathrm{C}$. $\mathrm{HfSi}_{\mathrm{x}} \mathrm{O}_{\mathrm{y}} \mathrm{N}_{\mathrm{z}}$ films are thermally stable after a "spike" anneal at $1050^{\circ} \mathrm{C}$ for $1 \mathrm{sec}$, but crystallization was observed after 60 sec. Z.A. $=\mathrm{Si}[110]$. 